\title{
Vedolizumab combined with surgical resection successfully treated perforating Crohn's disease with peritoneal space to rectal and vaginal fistulas: a case report
}

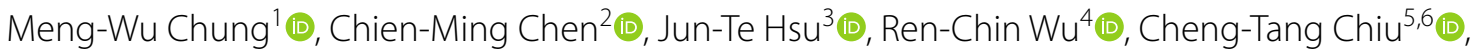 \\ Chia-Jung Kuo ${ }^{5,6}$ (D), Ming-Yao Su ${ }^{6,7}$ (D) and Puo-Hsien Le $5^{5,6,8^{*}}$ (])
}

\begin{abstract}
Background: Intestinal perforations and fistulas are common complications of Crohn's disease. However, chronic perforation with peritoneal space to rectal and vaginal fistulas have not been previously reported.

Case presentation: A 38-year-old female suffered from progressive lower abdominal pain, diarrhea and weight loss. Terminal ileal chronic perforation with intra-abdominal abscess, peritoneal space to rectal and vaginal fistulas were noted. The patient received surgical resection of the cecum and terminal ileum, and then vedolizumab treatment. Three months later, she had complete fistula closure, and her body mass index had increased from 13 to 22.

Conclusion: Vedolizumab combined with stool diversion is effective at treating Crohn's disease with chronic perforation and complex peritoneal space to rectal and vaginal fistulas.
\end{abstract}

Keywords: Vedolizumab, Surgery, Crohn's disease, Perforation, Fistula

\section{Background}

Crohn's disease (CD) is characterized by transluminal inflammation of the bowel; penetrating complications are often observed, such as intra-abdominal abscesses or fistulas, which are present in approximately $10-30 \%$ of patients at the time of diagnosis [1-4]. However, to the best of our knowledge, no cases of peritoneal space to rectal and vaginal fistulas have been previously reported. The management of intra-abdominal abscess with complex fistulas is challenging and requires a multidisciplinary approach, including percutaneous abscess drainage,

\footnotetext{
${ }^{*}$ Correspondence: puohsien@gmail.com

${ }^{5}$ Department of Gastroenterology and Hepatology, Chang Gung Memorial Hospital, Linkou Branch, Chang Gung University College of Medicine, 5, Fu-Hsin Street, Guei-Shan District, Taoyuan City 33305, Taiwan

Full list of author information is available at the end of the article
}

surgical resection and biological treatment [5]. The nonperianal fistula closure rate of tumor necrosis factor (TNF) antagonist is $13-28 \%$, but limited data is available for vedolizumab $[6,7]$. We present a patient who had CD with chronic terminal ileal perforation and peritoneal space to rectal and vaginal fistulas. The patient had complete fistula closure after a combination of surgery and vedolizumab treatment.

\section{Case presentation}

This 38-year-old female patient, with a body mass index (BMI) of 13, had suffered from progressive lower abdominal pain and intermittent fever for 3 months. She also had lost $32 \mathrm{~kg}$ of her body weight within 5 years. This time, the patient complained of progressive watery diarrhea for 2 weeks, and then visited our emergency department in November 2018. Due to her history of hyperthyroidism, 
she was first treated for a thyroid storm, and then admitted for further investigation due to her normal thyroid function.

The patient's history of past illness includes an episode of esophageal ulcer, 33-38 cm level from the incisor, diagnosed in December 2017, status post proton pump inhibitor treatment, complicated with stricture in March 2018, status post endoscopic dilatation in August 2018 (Fig. 1). Pathologist found granulation tissue with acute and chronic inflammation with necrotic tissue. Besides, she also had hyperthyroidism under methimazole use since 2002 and history of coronary arterial disease, one vessel disease, right coronary artery, status post two bare metal stents and one drug-eluting stent insertion in January 2016 and February 2017, under aspirin use.

After admission, physical examination found lower abdominal tenderness and tympanic sound to percussion, but no peritoneal signs. Laboratory survey revealed white blood cell count of $17,600 / \mu \mathrm{L}$, segment $86 \%$, myelocyte $0.5 \%$, band $1 \%$, lymphocyte $7 \%$, monocyte $5.5 \%$, hemoglobin $5.1 \mathrm{~g} / \mathrm{dL}$, platelet count $79,5000 / \mu \mathrm{L}$, alanine aminotransferase (ALT) $9 \mathrm{U} / \mathrm{L}$, sodium $(\mathrm{Na}) 127 \mathrm{mEq} / \mathrm{L}$, potassium (K) $3.2 \mathrm{mEq} / \mathrm{L}$, C-Reactive protein (CRP) $122.3 \mathrm{mg} / \mathrm{L}$, free-T4, $0.91 \mathrm{ng} / \mathrm{dL}$ and thyroid-stimulating hormone (TSH)1.159 uIU/mL. Tests for cytomegalovirus (CMV) DNA, Epstein-Barr virus (EBV)- viral capsid antigen (VCA) IgM, human immunodeficiency virus (HIV) antibodies (Ab), amebic Ab, and cultures for Salmonella, Shigella, Campylobacter and pus cells in the stool were all negative. Positive CMV IgM, CMV IgG, EBV-VCA IgG and occult blood were noted. Computed tomography (CT) revealed wall thickening over the ascending colon, cecum and terminal ileum (Fig. 2A), a suspicious terminal ileal perforation tract with a thick enhanced wall (Fig. 2B) and irregular shaped fluid and gas collection with a thick, enhanced wall, extending from the upper to the lower peritoneal cavity and cul-de-sac, which measured up to $14 \mathrm{~cm}$ (Fig. 2C, D). Antibiotic treatment with piperacillin/ tazobactam was then administered and CT guided drainage was arranged. Ganciclovir IVF was also prescribed from 2nd December 2018 to 17th January 2019 due to the CMV IgM positive, DNA negative finding. Abscess culture grew Enterococcus faecium and Candida glabrata. Antifungal treatment with anidulafungin was prescribed from the 7th December 2018 to 24th January 2019. A colonoscopy showed deep ulcers over the ileocecal valve (ICV) (Fig. 3A) and proximal A-colon with ICV stricture (Fig. 3B). The pathologist noted ulcers, and the remaining mucosa showed crypt branching, crypt shortening, and pyloric metaplasia. This was compatible with Crohn's disease with a negative immunohistochemistry for CMV, which was performed with a monoclonal antibody directed against the CMV pp65 antigen (Novocastra $^{\mathrm{TM}}$ lyophilized mouse monoclonal antibody; Leica Microsystems, Wetzlar, Germany). This led to a diagnosis of Crohn's disease with a Montreal classification of A2L3L4B2B3, a Crohn's disease activity index (CDAI) of 623 points and a Harvey-Bradshaw Index (HBI) of 22 points. After infection control, oral prednisolone $20 \mathrm{mg} / \mathrm{D}$ and azathioprine $25 \mathrm{mg} / \mathrm{D}$ were prescribed. We stopped the azathioprine treatment due to nausea and vomiting side effects. The patient was discharged with oral prednisolone $20 \mathrm{mg}$ and oral levofloxacin in January 2019. One month later, she complained of stool-like

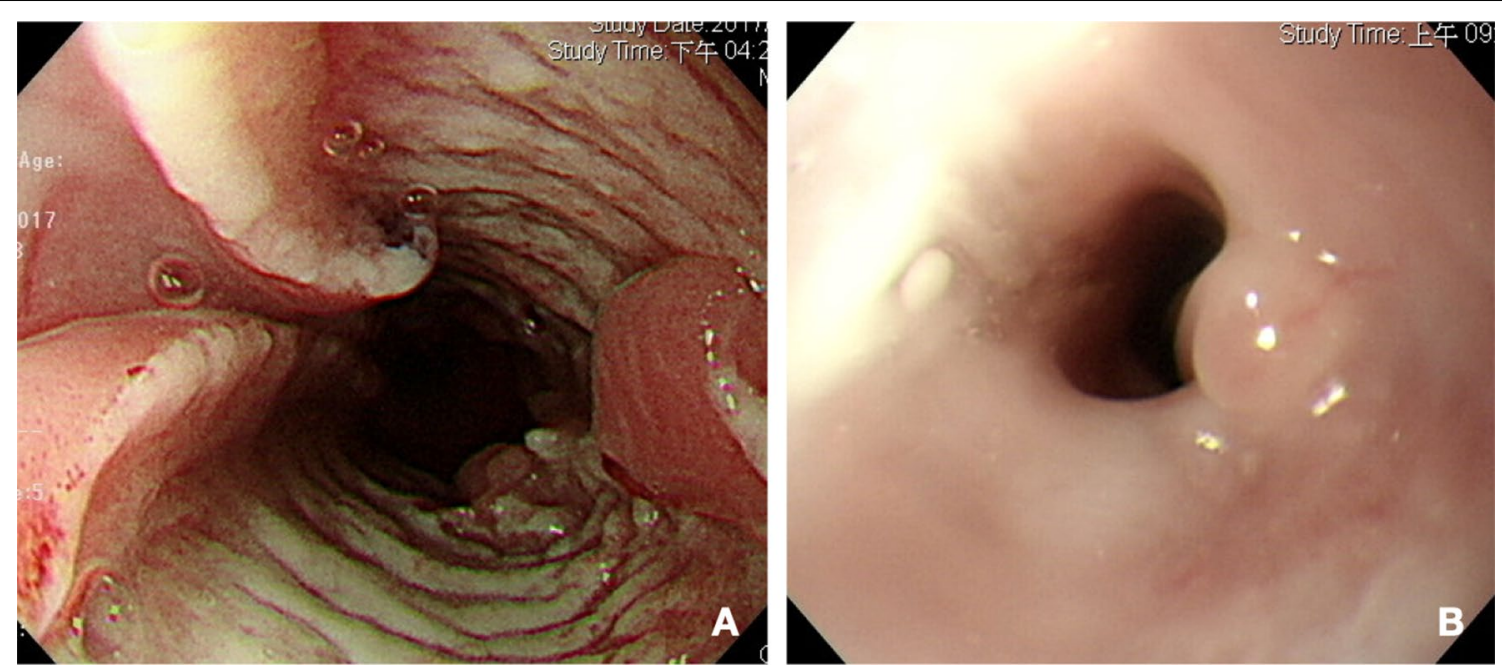

Fig. 1 Esophagogastroduodenoscopy (EGD). A Esophageal deep ulcer, 33-38 cm from the incisor. B Esophageal stricture after 3 months of proton pump inhibitor treatment 

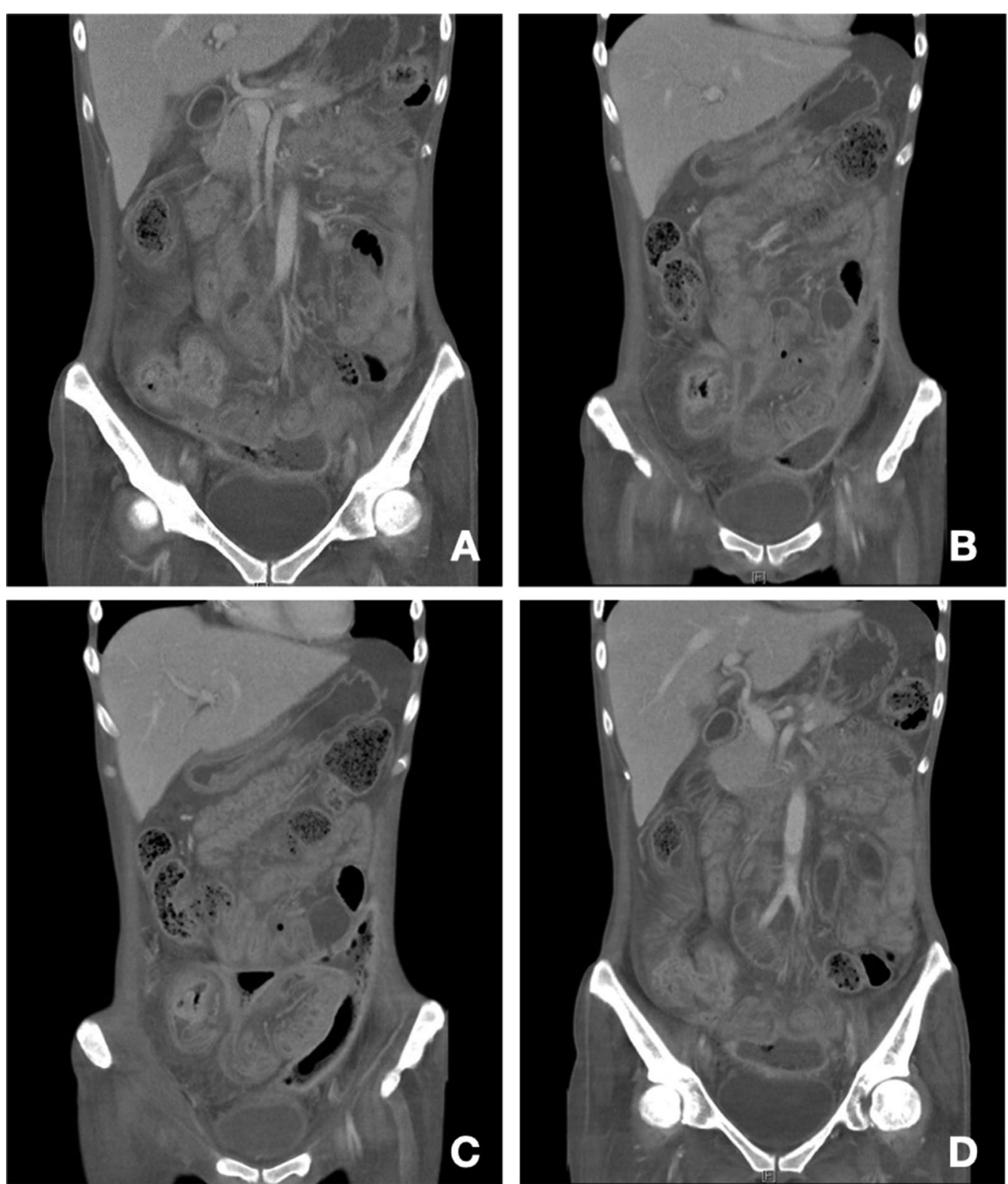

Fig. 2 Computed tomography of the abdomen at diagnosis. A Wall thickening over the ascending colon, cecum and terminal ileum. B Suspicious terminal ileal perforation tract with a thick enhanced wall. C, D Irregular shaped fluid and gas collection with a thick, enhanced wall, extending from the upper to lower peritoneal cavity and cul-de-sac

discharge from the vagina. A fistulogram through the vagina revealed peritoneal space to rectal and vaginal fistulas (Fig. 4A).

The final diagnosis was Crohn's disease, with a Montreal classification of A2L3L4B2B3, which was complicated by an esophageal ulcer with stricture and chronic terminal ileal perforation with peritoneal space to rectal and vaginal fistulas.

The patient received surgical resection of the cecum, terminal ileum and chronic perforated tract over the terminal ileum, and ileo-colostomy side to side anastomosis and an end-ileostomy on the 1st April 2019. The pathologist noted that the entire specimen measured $9.5 \times 8.0 \times 5.5 \mathrm{~cm}$. The intestine showed ulceration, pseudopolyps, and a fistular tract surrounded by purulent exudate (Fig. 5A). These microscopic findings were compatible with the diagnosis of Crohn's disease (Fig. 5B-D). She had no more stool like material passing out from her vagina 1 week later. The patient was prescribed vedolizumab treatment with standard induction and 

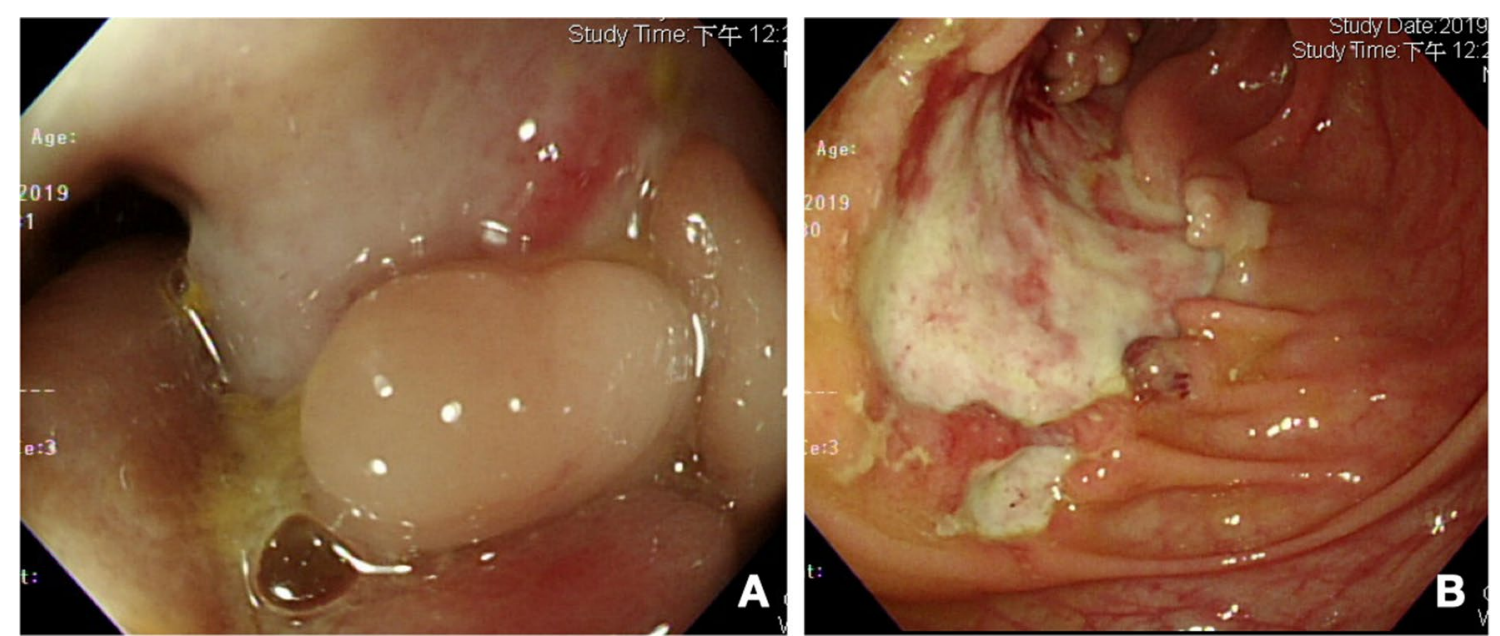

Fig. 3 Colonoscopy at diagnosis. A lleocecal valve ulcer with stricture. B Scending colon ulcer
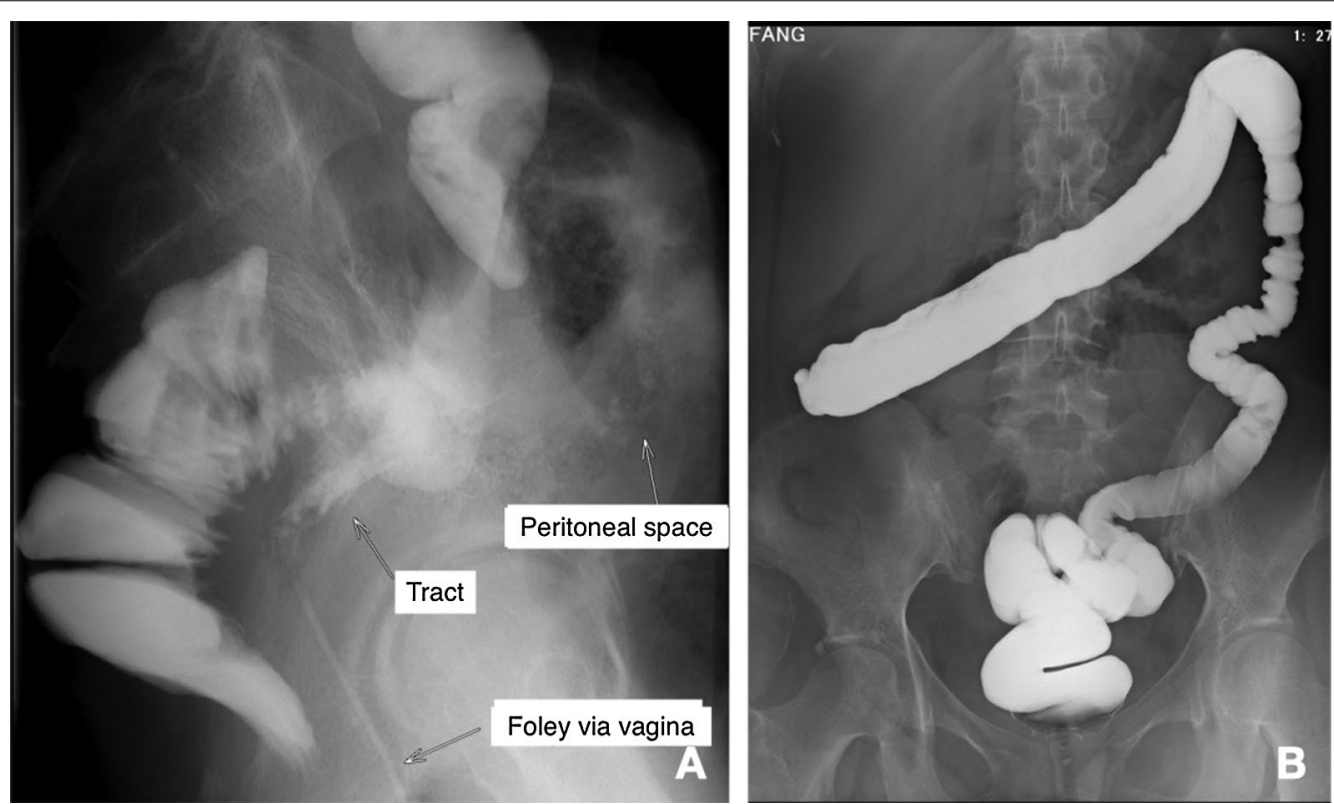

Fig. 4 Lower gastrointestinal (LGI) study. A The vagina was marked by a Foley catheter. It showed peritoneal space to rectal and vaginal fistulas. B No more fistula tract was noted after 6 months treatment

maintenance dose (300 mg in 0th week, 2nd week, 6th week, and then every 8 weeks) on the 24th April 2019.

In July 2019, the patient underwent colonoscopy examination, which only showed mild inflammatory activity over the blind end, and a lower gastrointestinal (LGI) series also noted no more fistula. Closure of the end-ileostomy with an end-to-side ileo-ascending-colon anastomosis was performed in August 2019. A lower gastrointestinal tract X-ray examination was arranged, which revealed no remaining fistula or obstruction
(Fig. 4B). The patient regained $23 \mathrm{~kg}$ of body weight, with her BMI increasing from 13 to 22. Her CDAI dropped from 623 to 4 points and her $\mathrm{HBI}$ fell from 22 to 0 points.

\section{Discussion and conclusion}

The management of nonperianal penetrating Crohn's disease with abscess is always challenging because not only the inflammation but also the infection [8] needs to be controlled. Percutaneous drainage with antibiotic treatment can prevent $30 \%$ of Crohn's disease patients with 

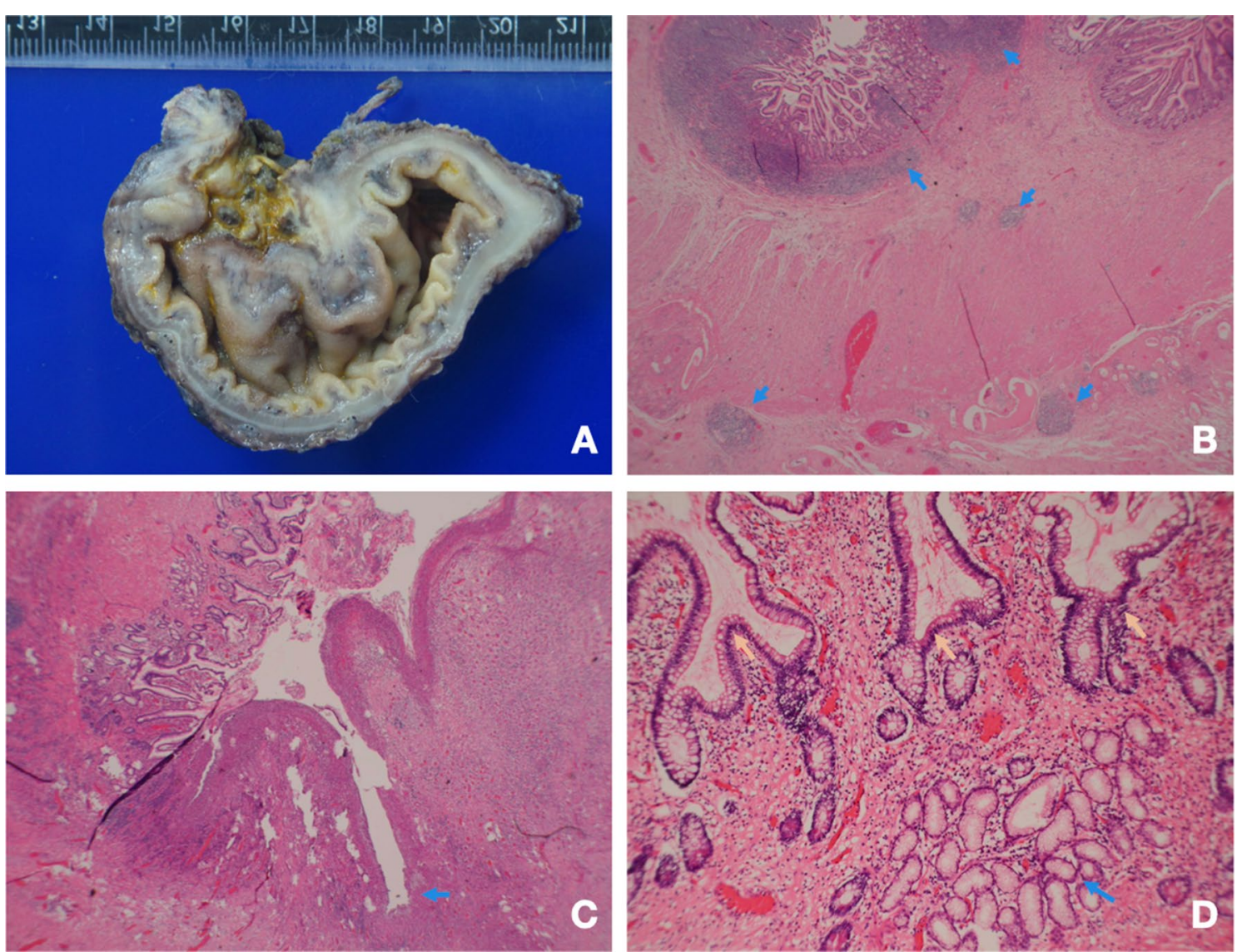

Fig. 5 Pathological presentation of Crohn's disease. A Dense fibrous fistula from the terminal ileum. B Arrow: lymphoid follicles, demonstrating transmural involvement. C Arrow: a fissure. The remaining mucosa on the left shows marked crypt distortion. D Blue arrow: crypt branching. Yellow arrow: pyloric metaplasia (both are features of chronicity)

intra-abdominal abscesses from requiring surgery [9]. Anti-TNF alpha agents, especially infliximab, with the strongest evidence in treating fistulizing Crohn's disease, with a $14-25 \%$ response rate for internal fistulas [10-13], and a $30-50 \%$ fistula closure rate for kinds of fistulas [1416]. Vedolizumab, a gut-selective $\alpha 4 \beta 7$ integrin antagonist, also showed a $31 \%$ fistula closure rate at Week 52 in the GEMINI 2 trial [16], although there was a small sample size and limited other evidence. However, compared with anti-TNF antagonists, vedolizumab had less severe infection and adverse effects in a real world study [17]. Therefore, in patients with Crohn's disease who have an infection or are at high risk of progressive infection, it might be the optimal choice. In this complex case, early percutaneous drainage, surgical diversion and early biological treatment led to a favorable outcome.

In conclusion, a multidisciplinary approach is critical when treating perforating Crohn's disease with intraabdominal abscess and complex fistula, to ensure successful management of the condition. As far as biologics is concerned, vedolizumab could be the optimal choice due to the lower risk of worsening the infection and its fair ability to control the inflammation. Larger welldesigned studies are required to thoroughly assess the effectiveness of vedolizumab in treating complex fistulizing Crohn's disease.

\section{Abbreviations}

CD: Crohn's disease; TNF: Tumor necrosis factor; BMI: Body mass index; ALT: Alanine aminotransferase; Na: Sodium; K: Potassium; CRP: C-reactive protein; TSH: Thyroid-stimulating hormone; CMV: Cytomegalovirus; EBV: Epstein-Barr virus; VCA: Viral capsid antigen; HIV: Human immunodeficiency virus; Ab: Antibody; CT: Computed tomography; IVF: Intravenous fluid; ICV: Ileocecal valve; CDAl: Crohn's disease activity index; HBI: Harvey-Bradshaw index; LGI: Lower gastrointestinal.

\section{Acknowledgements}

The authors would like to thank the inflammatory bowel disease team of Chang Gung Memorial Hospital for their great effort.

\section{Authors' contributions}

MWC wrote the manuscript; PHL decided the treatment plan, wrote and revised the manuscript; JTH decided the surgical plan; CMC analyzed the radiological images; RCW interpreted the pathological result; CTC, CJK and MYS acquired and analyzed the data. All authors read and approved the final manuscript. 


\section{Funding}

No funding was received.

\section{Availability of data and materials}

The datasets used and/or analysed during the current study are available from the corresponding author on reasonable request.

\section{Declarations}

\section{Ethics approval and consent to participate}

The study was performed in accordance with the Declaration of Helsinki, and needs no ethics approval. Written informed consent for participation was obtained from the patient.

\section{Consent for publication}

Written informed consent for publication was obtained from the patient.

\section{Competing interests}

The authors have no conflict of interest to declare.

\section{Author details}

'Department of Medical Education, Chang Gung Memorial Hospital, Linkou Branch, Taoyuan, Taiwan. ${ }^{2}$ Department of Medical Imaging and Interventions, Chang Gung Memorial Hospital, Linkou Branch, Taoyuan, Taiwan. ${ }^{3}$ Department of General Surgery, Chang Gung Memorial Hospital, Linkou Branch, Taoyuan, Taiwan. ${ }^{4}$ Department of Pathology, Chang Gung Memorial Hospital, Linkou Branch, Taoyuan, Taiwan. ${ }^{5}$ Department of Gastroenterology and Hepatology, Chang Gung Memorial Hospital, Linkou Branch, Chang Gung University College of Medicine, 5, Fu-Hsin Street, Guei-Shan District, Taoyuan City 33305, Taiwan. ${ }^{6}$ Taiwan Association of the Study of Small Intestinal Disease, Taoyuan, Taiwan. ${ }^{7}$ Department of Gastroenterology and Hepatology, New Taipei City Municipal Tucheng Hospital, New Taipei City, Taiwan. ${ }^{8}$ Liver Research Center, Chang Gung Memorial Hospital, Linkou Branch, Taoyuan, Taiwan.

Received: 20 April 2021 Accepted: 6 July 2021

Published online: 29 July 2021

\section{References}

1. Hirten RP, Shah S, Sachar DB, Colombel J-F. The management of intestinal penetrating Crohn's disease. Inflamm Bowel Dis. 2018;24(4):752-65.

2. Thia KT, Sandborn WJ, Harmsen WS, Zinsmeister AR, Loftus EV Jr. Risk factors associated with progression to intestinal complications of Crohn's disease in a population-based cohort. Gastroenterology. 2010;139(4):1147-55.

3. Peyrin-Biroulet L, Loftus EV Jr, Colombel J-F, Sandborn WJ. The natural history of adult Crohn's disease in population-based cohorts. Am J Gastroenterol. 2010;105(2):289-97.
4. de Groof EJ, Carbonnel F, Buskens CJ, Bemelman WA. Abdominal abscess in Crohn's disease: multidisciplinary management. Dig Dis. 2014;32(Suppl. 1):103-9.

5. de Campos-Lobato LF, Kiran RP. Surgical management of complex enteric fistulas in Crohn's disease. Clin Colon Rectal Surg. 2019;32(4):268-72.

6. Rozpondek P, Zwolińska-Wcisło M, Przybylska M, Mach T. Effectiveness of anti-TNF alpha antibodies in treatment of fistulizing Crohn's disease. Przegl Lek. 2011;68(9):602-5.

7. Gómez-Senent S, Barreiro-de-Acosta M, García-Sánchez V. Enterocutaneous fistulas and Crohn's disease: clinical characteristics and response to treatment. Rev Esp Enferm Dig. 2013;105(1):3-6.

8. Hirten RP, Shah S, Sachar DB, Colombel JF. The management of intestinal penetrating Crohn's disease. Inflamm Bowel Dis. 2018;24(4):752-65.

9. Clancy C, Boland T, Deasy J, McNamara D, Burke JP. A meta-analysis of percutaneous drainage versus surgery as the initial treatment of Crohn's disease-related intra-abdominal abscess. J Crohns Colitis. 2016;10(2):202-8.

10. Parsi MA, Lashner BA, Achkar JP, Connor JT, Brzezinski A. Type of fistula determines response to infliximab in patients with fistulous Crohn's disease. Am J Gastroenterol. 2004;99(3):445-9.

11. Kim SH, Yang S, Kim KJ, Kim EH, Yoon SM, Ye BD, et al. Efficacy of infliximab in the treatment of korean patients with crohns disease. Korean J Gastroenterol. 2009:54(2):108-16.

12. Nunes J, Santos PM, Tavares L. Complete resolution of enterocolic fistulas with infliximab. BioDrugs. 2010;24(Suppl 1):28-30.

13. Teitelbaum JE, Saeed S, Triantafyllopoulou M, Daum F. Infliximab in pediatric Crohn disease patients with enterovesicular fistulas. J Pediatr Gastroenterol Nutr. 2007:44(2):279-82.

14. Present DH, Rutgeerts P, Targan S, Hanauer SB, Mayer L, Van Hogezand $R$, et al. Infliximab for the treatment of fistulas in patients with Crohn's disease. N Engl J Med. 1999;340(18):1398-405.

15. Schwartz D, Rutgeerts P, Colombel J, Sandborn W, Hanauer S, Kent J, et al. Induction, maintenance, and sustainability of the healing of draining fistulas in patients with Crohn's disease treated with adalimumab: results of the CHARM study: 1177. Off J Am Coll Gastroenterol ACG. 2006;101:S58-9.

16. Feagan BG, Schwartz D, Danese S, Rubin DT, Lissoos TW, Xu J, et al. Efficacy of vedolizumab in fistulising Crohn's disease: exploratory analyses of data from GEMINI 2. J Crohns Colitis. 2018;12(5):621-6.

17. Lukin D, Weiss A, Aniwan S, Kadire S, Tran G, Rahal M, et al. DOP009 Comparative safety profile of vedolizumab and tumour necrosis factor-antagonist therapy for inflammatory bowel disease: a multicentre consortium propensity score-matched analysis. J Crohn's Colitis. 2018;12(Supplement_1):S036-S.

\section{Publisher's Note}

Springer Nature remains neutral with regard to jurisdictional claims in published maps and institutional affiliations.
Ready to submit your research? Choose BMC and benefit from:

- fast, convenient online submission

- thorough peer review by experienced researchers in your field

- rapid publication on acceptance

- support for research data, including large and complex data types

- gold Open Access which fosters wider collaboration and increased citations

- maximum visibility for your research: over $100 \mathrm{M}$ website views per year

At BMC, research is always in progress.

Learn more biomedcentral.com/submissions 